\title{
Effects of mitotane on testicular adrenal rest tumors in congenital adrenal hyperplasia due to 21-hydroxylase deficiency: a retrospective series of five patients
}

\author{
Anne Bachelot ${ }^{1,2}$, Marion Lapoirie ${ }^{3}$, Jérôme Dulon', Monique Leban ${ }^{4}$, Raphaële Renard Penna ${ }^{2,5}$ and \\ Philippe Touraine ${ }^{1,2}$
}

${ }^{1}$ AP-HP, IE3M, Hôpital Pitié-Salpêtrière, Department of Endocrinology and Reproductive Medicine and Centre de Référence des Maladies Endocriniennes Rares de la Croissance et du Développement, Paris, France, ${ }^{2}$ Sorbonne Université, Paris, France, ${ }^{3}$ Department of Endocrinology, Hospices Civils de Lyon, Fédération d'Endocrinologie, Bron, France, ${ }^{4}$ AP-HP, Hôpital Pitié-Salpêtrière, Department of Hormonal Biochemistry, and ${ }^{5}$ AP-HP, Hôpital PitiéSalpêtrière, Department of Radiology, Paris, France

\author{
Correspondence \\ should be addressed \\ to A Bachelot \\ Email \\ anne.bachelot@aphp.fr
}

\begin{abstract}
We conducted a retrospective study on the long-term effect of mitotane treatment on testicular adrenal rest tumors (TARTs) in five adult patients with classic 21-hydroxylase deficiency. After 60 months of mitotane treatment, a decrease in adrenal steroids was observed in four patients. Testicular ultrasonography showed complete disappearance of TART in two patients, stabilization in two patients and a halving of TART volume in the remaining patient. Sperm count improved notably in two patients who had normal baseline inhibin B levels and small inclusions, thus enabling cryopreservation of the subjects' semen. Four years of follow-up of these two patients after the withdrawal of mitotane showed no recurrence of TART and persistent normal testicular function. In conclusion, mitotane could be used as a last resort in CAH patients in the cases of azoospermia associated with TARTs but normal inhibin B levels, as it can improve long-term endocrine and exocrine testicular function.
\end{abstract}

\section{Introduction}

Twenty-one-hydroxylase deficiency (21OHD) is the most common form of congenital adrenal hyperplasia (CAH). Male patients with CAH may present impaired testicular function and infertility (1). Testicular adrenal rest tumors (TARTs) have been described in these patients $(1,2,3$, 4) and have been demonstrated to constitute one of the most important causes of infertility. In recent studies, the overall prevalence of TARTs in classic CAH patients was $40 \%(1,2,3,4,5,6)$. TARTs appear to be associated with poor hormonal control and concomitant elevated adrenocorticotropic hormone (ACTH) $(7,8)$. Molecular characterization of TARTs has shown that these tumors have multiple steroidogenic properties, including the expression of adrenal cortex and typical Leydig cell markers (9), leading to the hypothesis of pluripotent cells as the origin of TARTs (3). To date, there are no methods to prevent the development of TARTs, nor are there guidelines to treat patients with TARTs (3). Systematic ultrasound evaluation is recommended at puberty to detect lesions at an early stage. A semen analysis should also be done as soon as possible, and the question of systematic sperm cryopreservation seems fully justified (3). Treatment options for male patients with TARTs are still limited and mainly based on good hormonal control 
with glucocorticoids $(3,10,11)$. However, long-term high doses of glucocorticoids do not always restoretesticular function and often have unacceptable side effects (3).

Mitotane, 1,1-dichloro-2-(o-chlorophenyl)-2-( $p$ chloro-phenyl) ethane, has been used for several decades to treat adrenal carcinoma and Cushing's syndrome based on its potent adrenotoxic effects $(12,13,14)$ and capacity to blockcortisol synthesis by inhibiting $11 ß$-hydroxylation andcholesterol chain cleavage. Recently, Bry-Gaillard et al. have shown that mitotane could restore fertility in CAH patients with TARTs (15). In this study, we suggest that long-term mitotane treatment is able to shrink adrenal rest tumors, improve sperm count and adrenal secretion in five adult patients with classical $\mathrm{CAH}$ due to 21OHD presenting testicular adrenal rest tumors in whom intensified glucocorticoid therapy was inefficient or impossible due to major side effects.

\section{Patients and methods}

\section{Patients}

Medical files from five patients were recorded retrospectively. The main clinical features are summarized in Table 1. All patients were diagnosed as newborns with a salt-wasting form of $\mathrm{CAH}$ due to 21-hydroxylase deficiency. They were treated with hydrocortisone and mineralocorticoids. Patients 1, 3 and 4 were homozygous for an IVS2 splice mutation, patient 2 was compound heterozygous for a large lesion and L307fs, and patient 5 was compound heterozygous for R386W and a large lesion. Testicular adrenal rest tumors were diagnosed by testicular ultrasonography in all patients except patient 4 , in whom TARTs were diagnosed by clinical examination. Semen analysis showed complete azoospermia in patients 1 and 3 and oligospermia in patients 2 and 5 . Semen analysis was not possible in patient 4 (anejaculation). None of these patients had fathered children at baseline. The five patients were treated with glucocorticoids and mineralocorticoids (Fig. 1) and had already increased their doses of glucocorticoid treatment without any efficacy in reducing TARTs volume. Furthermore, they had side effects of weight gain or osteopenia in response to the glucocorticoid therapy.

Each patient underwent regular follow-up, including routine biochemistry, endocrine work-ups, and physical examinations, to monitor the safety and efficacy of the treatment. The endocrine work-ups included fasting blood samples to ascertain levels of measurement of plasma 17OH-progesterone, testosterone ( $\mathrm{T})$, androstenedione $(\mathrm{A})$, ACTH, renin, testosterone, sex hormone binding globulin (SHBG), LH, FSH and inhibin B, in the morning, before medications. Semen analysis was performed according to the World Health Organization (WHO) guidelines. Each patient had testicular imaging at 6 months, then at 12 months (except patient 3 and 4), 24 months (except patient 4), 36 months and 60 months (except patient 2). A testicular sonogram was performed on each patient, except for patient 2 who underwent testicular MRI. Treatment compliance was assessed by monitoring plasma mitotane levels every 6 months $(14,16)$.

In France, retrospective studies such as ours do not require institutional review board/institutional ethics committee approval to analyze the data and publish the results.

\section{Methods}

Mitotane therapy

Mitotane treatment (Lysodren, HRA; $500 \mathrm{mg}$ tablets) was proposed to the five patients. It was administered orally at

Table 1 Clinical and ultrasonographic characteristics of the $5 \mathrm{CAH}$ patients.

\begin{tabular}{|c|c|c|c|c|c|}
\hline & Patient 1 & Patient 2 & Patient 3 & Patient 4 & Patient 5 \\
\hline Age (years) & 24 & 20 & 21 & 28 & 24 \\
\hline Height (cm) & 162 & 172 & 172 & 163 & 165 \\
\hline $\mathrm{BMI}\left(\mathrm{kg} / \mathrm{m}^{2}\right)$ & 28 & 21 & 18 & 23 & 27 \\
\hline \multicolumn{6}{|l|}{ Treatment } \\
\hline $\mathrm{HC}$ (mg/day) & 25 & 40 & 25 & 30 & 40 \\
\hline FC ( $\mu g / d a y)$ & 100 & 100 & 50 & 150 & 100 \\
\hline Testicular volume (left/right, mL) & $7 / 5$ & $18 / 16$ & $9 / 11$ & $19 / 25$ & $12.5 / 13$ \\
\hline \multicolumn{6}{|l|}{ TART volume (left/right, mL) } \\
\hline Baseline & $0.8 / 1$ & $8 / 8$ & $5 / 6$ & $4 / 2.5$ & $0.3 / 0.2$ \\
\hline 24 months & $0 / 0$ & $4 / 2.1$ & $4 / 6$ & & $0 / 0$ \\
\hline 36 months & $0 / 0$ & $5 / 6$ & $5 / 4.5$ & $2.5 / 2.7$ & $0 / 0$ \\
\hline 60 months & $0.1 / 0.2$ & & $4 / 6.5$ & $2.6 / 2.1$ & $0 / 0$ \\
\hline
\end{tabular}



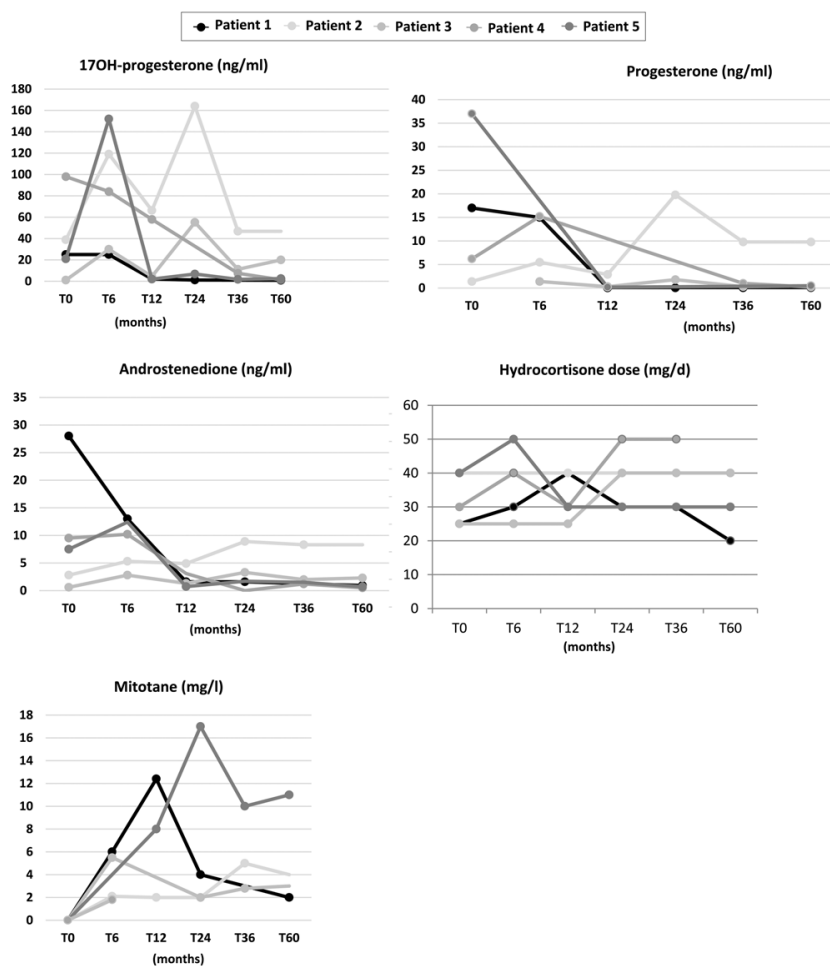

\section{Figure 1}

Adrenal steroids, hydrocortisone dose and mitotane levels at baseline and during mitotane treatment. Normal baseline values: $170 \mathrm{H}$-progesterone $(\mathrm{ng} / \mathrm{mL})$ 0.6-3.4; androstenedione $(\mathrm{ng} / \mathrm{mL})$ 0.2-2.9; progesterone $(\mathrm{ng} / \mathrm{mL})$ 0.2-1.4.

a starting dose of $0.5-1 \mathrm{mg}$ daily and then increased to 2-3 g daily or the highest tolerated dose. The dose was adjusted by monitoring plasma mitotane levels to maintain drug concentrations under $14 \mu \mathrm{g} / \mathrm{mL}$, thus avoiding toxicity. The highest doses were $0.5 \mathrm{~g} /$ day in patient $1,4 \mathrm{~g} /$ day in patient 2, $1 \mathrm{~g}$ /day in patient 3, $2.5 \mathrm{~g}$ /day patient 4 and 3 g/day in patient 5 . Patients 1, 2, 3 and 5 were treated for 5 years. Patient 3 interrupted treatment for approximately 18 months following the occurrence of acute adrenal insufficiency. Patient 4 had to stop treatment after only 1 year due to poor digestive tolerance. During treatment, the dose of steroid coverage in the five patients was increased to prevent adrenal insufficiency. Discontinuation of treatment was decided according to the response to treatment (improvement or even normalization of sperm analysis, decrease or disappearance of inclusions on ultrasound), or in case of poor tolerance to treatment.

\section{Data analysis}

The results are presented as the mean \pm s.D. if not stated otherwise.

\section{Results}

\section{Adrenal steroids}

As shown in Fig. 1, 17OHP, progesterone and A levels were very high at baseline in four of the five patients. Only patient 3 showed a good hormonal balance under treatment, with $17 \mathrm{OHP}$ levels at $2.0 \mathrm{ng} / \mathrm{mL}$ and A levels at $0.65 \mathrm{ng} / \mathrm{mL}$. During treatment, the $17 \mathrm{OHP}$ and A levels of patients 2 remain elevated. After 12 months of treatment, there was a median decrease of $88 \%$ of serum $17 \mathrm{OHP}$ levels and of $57 \%$ of serum A levels in the three remaining patients (Fig. 1). Thereafter, hormonal control remained stable during treatment with mitotane, except in patient 2, in whom $17 \mathrm{OHP}, \mathrm{A}$ and progesterone increased concomitantly with poor compliance with treatment. This was confirmed by the mitotane levels, which remained low during the first 2 years of treatment ( $<2 \mathrm{mg} / \mathrm{L})$ (Fig. 1).

\section{Testicular function and morphological evaluation of TART}

The evolution of testicular hormonal function is represented in Table 2. At the initial evaluation, basal serum LH and FSH levels werelow in patients 1 and 5, indicating gonadotrophin insufficiency. After 24 months of mitotane treatment, there was a recovery of gonadotropin secretion, and total testosterone levels increased, due to elevated SHBG, which is generally associated with mitotane treatment.Patient 2 had moderate testicular insufficiency after 24 months of treatment. Patients 3 and 4 showed elevated gonadotrophin levels, reflecting testicular failure.

The results of testicular investigations are presentedin Fig. 2 and Table 1. Each patient had testicular imaging at 6 months, showing no change of TARTs volume. In patients 1 and 5, there was a near disappearance of the intratesticular masses by ultrasonography and MRI at 24 months, concomitant with the normalization of sperm count. By ultrasonography, there was a relative stability of TART volume during mitotane treatment in patients 3 and 4 and a halving of TART volume in patient 2 .

The sperm count results before and during mitotane treatment are presented in Table 3. Patients 1 and 5 showed normalized sperm count during treatment, which allowed for the storage of their semen by cryopreservation. Patient 2 had severe oligospermia and azoospermia 6 months later. This patient had the largest TART. No sperm analysis was done during the therapy with mitotane in patients 3 and 4 , for personal reasons. 
Table 2 Evolution of testicular function in CAH patients at baseline and during mitotane treatment.

\begin{tabular}{|c|c|c|c|c|c|c|}
\hline & Normal range & Patient 1 & Patient 2 & Patient 3 & Patient 4 & Patient 5 \\
\hline FSH (IU/L) & $1.5-12.4$ & & & & & \\
\hline Baseline & & 0.1 & 9.8 & 17 & 7.1 & 1.2 \\
\hline $\mathrm{T} 12$ & & 3.3 & ND & 8.7 & 4.1 & 5.2 \\
\hline T24 & & 7.5 & 8.1 & 13.1 & ND & 9.1 \\
\hline T36 & & 6.7 & 14.4 & 18.1 & 15 & ND \\
\hline T60 & & 3.6 & ND & 14.8 & ND & 8.2 \\
\hline LH (IU/L) & $1.5-8.6$ & & & & & \\
\hline Baseline & & 0.34 & 9.3 & 11.2 & 9.2 & 1.1 \\
\hline T12 & & 9.1 & & 11.4 & 4 & 4.3 \\
\hline T24 & & 14 & 11.3 & 12 & ND & 15.2 \\
\hline T36 & & 11.3 & 11.6 & 10.4 & ND & 9.8 \\
\hline T60 & & 5.4 & ND & 10 & 9.8 & 2.7 \\
\hline Total TS (ng/mL) & $2.5-8.4$ & & & & & \\
\hline Baseline & & 5.7 & 8.8 & 5 & 6.2 & 3.4 \\
\hline T12 & & 17.5 & 2.9 & 9.8 & 4.1 & 9.5 \\
\hline T24 & & 19 & 7.3 & 9.3 & ND & 29 \\
\hline T36 & & 9.3 & 11.2 & 11.0 & 3.7 & 17 \\
\hline T60 & & 7.5 & ND & 12.8 & ND & 8.6 \\
\hline SHBG (nmol/L) & $16.5-55.9$ & & & & & \\
\hline Baseline & & 50 & 43 & 34 & 30 & 32 \\
\hline $\mathrm{T} 12$ & & 220 & 68.4 & 78 & ND & 244 \\
\hline T24 & & 128 & 113 & 46 & ND & 172 \\
\hline T36 & & 77 & 142 & 61 & 27 & 124 \\
\hline T60 & & 70 & ND & 81 & 27 & 87 \\
\hline Inhibin B (pg/mL) & $25-325$ & & & & & \\
\hline Baseline & & 128 & 131 & 15 & 31 & 167 \\
\hline T12 & & 167 & 60 & 71 & 40 & 111 \\
\hline T24 & & ND & 46 & 67 & ND & ND \\
\hline T36 & & ND & 39 & 43 & 42 & 126 \\
\hline T60 & & 152 & 75 & 72 & 33 & 128 \\
\hline
\end{tabular}

ND, not determined; TS, testosterone.

\section{Safety}

Weight loss was observed in patients 1,2 and 5, at respectively $-8.1,-15.7$ and $-18.4 \%$. The weight remained stable for patient 3 , and patient 4 gained $9.5 \mathrm{~kg}$ in 6 months (+15.8\% under treatment). Patient 4 had to stop the treatment prematurely due to poor digestive tolerance (nausea and diarrhea). Patients 3 and 5 each experienced one episode of adrenal crisis during treatment, respectively after 20 and 5 months of treatment, requiring a short hospital stay for each, followed by discontinuation of treatment in patient 3 and a simple adjustment of glucocorticoid treatment in patient 5 . None of the patients require higher doses of fludrocortisone during therapy. Moderate elevation of LDL-c was observed during treatment, but this symptom resolved with reinforced dietary and lifestyle measures. No patients were treated with statins. Finally, hepatic cytolysis and minimal anicteric cholestasis $<1.5 \mathrm{~N}$ was observed in all patients except patient 2, with complete normalization after discontinuation of the treatment.

\section{Long-term follow-up}

Long-term follow-up after discontinuation of the treatment was available for patients 1, 4 and 5. Two years after the discontinuation of mitotane, patient 1 fathered a healthy child. His last ultrasound 4 years after the discontinuation of treatment found stable testicular volume, with minimal inclusions $\left(0.1 \mathrm{~cm}^{3}\right.$ on the right, $0.2 \mathrm{~cm}^{3}$ on the left), and hormonal assays showed normal testicular function (FSH $3.4 \mathrm{IU} / \mathrm{L}$, LH $5.2 \mathrm{IU} / \mathrm{L}, \mathrm{TT} 7 \mathrm{ng} /$ mL, SHBG $60 \mathrm{nmol} / \mathrm{L}$, inhibin B $178 \mathrm{ng} / \mathrm{mL}$ ).

One year after discontinuation of mitotane, patient 5 showed a decrease in sperm count, nevertheless allowing for semen cryopreservation. The last ultrasound done 6 years after stopping treatment found testicles of normal volume without TARTs, and normal testicular function (FSH $3.2 \mathrm{IU} / \mathrm{L}, \mathrm{LH} 5.4 \mathrm{IU} / \mathrm{L}$, TT $9.5 \mathrm{ng} / \mathrm{mL}$, SHBG 86 $\mathrm{nmol} / \mathrm{L}$, inhibin B $201 \mathrm{ng} / \mathrm{mL}$ ).

Five years after the 1 year treatment with mitotane, patient 4 still had moderate testicular insufficiency (FSH $13.3 \mathrm{IU} / \mathrm{L}, \mathrm{LH} 9.2 \mathrm{IU} / \mathrm{L}$, TT $6.4 \mathrm{ng} / \mathrm{mL}$, SHBG 38 

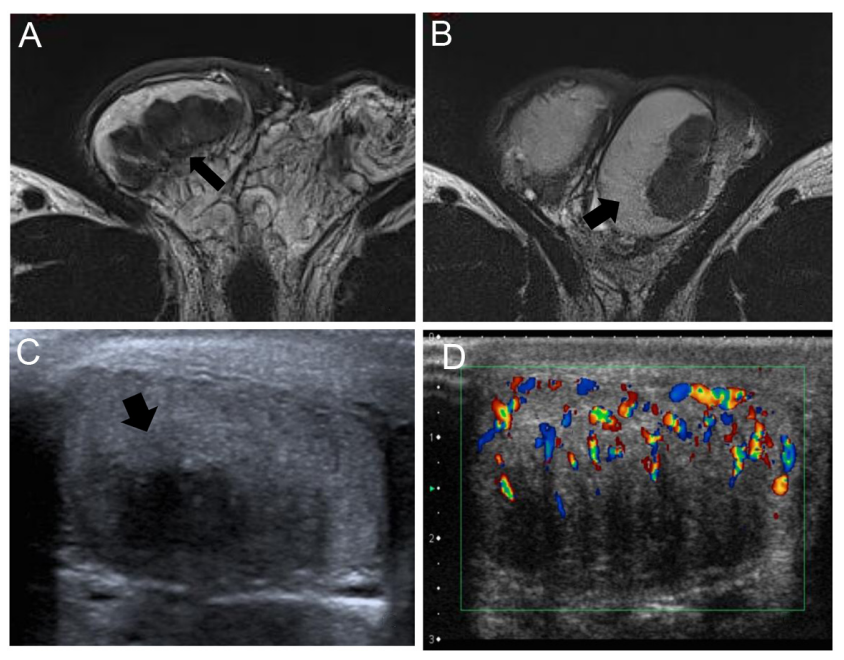

\section{Figure 2}

A 28-year-old man with adrenal hyperplasia who had bilateral testicular masses. T2 weighted axial MR ( $A$ and $B$ ) shows bilateral intratesticular masses that are hypointense compared with normal testicular tissues. Longitudinal sonogral of right testicule (C) shows large hypoechoic solid intratestcular masses with sound attenuation, avascular on Color Doppler sonogram (D). A full color version of this figure is available at https://doi.org/10.1530/EJE-20-0787.

nmol/L, inhibin B $33 \mathrm{ng} / \mathrm{mL}$ ) with bilateral testicular hypotrophy by ultrasound $\left(8 \mathrm{~cm}^{3}\right.$ on the right, $10 \mathrm{~cm}^{3}$ on the left), and increased inclusion volumes $\left(4 \mathrm{~cm}^{3}\right.$ on the right, $4.5 \mathrm{~cm}^{3}$ on the left). Semen analysis 5 years after stopping treatment showed cryptozoospermia (four spermatozoa).

\section{Discussion}

Until now, there have been no clear guidelines for the treatment or prevention of TARTs (3). The development of TARTs is generally understood to be the result of sustained elevation of plasma ACTH concentrations, usually associated with poor control of CAH. However, TARTs have also been reported in men with adequate control of CAHand, conversely, some subjects with poorly controlled CAH never develop TARTs despite chronically elevated ACTH levels. The first choice of treatment is intensification of glucocorticoid treatment to suppress ACTH, based on a few cases in which this has led to reduction of the tumor size and improved testicular function $(17,18,19,20)$. Hydrocortisone, dexamethasone, and prednisone were all used as treatment for TARTs (21). However, no prospective
Table 3 Evolution of sperm parameters in CAH patients at baseline, during mitotane treatment and after discontinuation of the treatment.

\begin{tabular}{|c|c|c|c|c|c|}
\hline & \multicolumn{5}{|c|}{ Sperm count $\left(\times 10^{6} / \mathrm{mL}\right)$} \\
\hline & Patient 1 & Patient 2 & Patient 3 & Patient 4 & Patient 5 \\
\hline Baseline & $A Z$ & 1.2 & 0.06 & AN & 15 \\
\hline At 12 months & 12 & $A Z$ & ND & ND & $A Z$ \\
\hline $\begin{array}{l}\text { At stoppage of } \\
\text { mitotane }\end{array}$ & 24 & ND & ND & ND & 39 \\
\hline \multicolumn{6}{|l|}{$\begin{array}{c}\text { After stoppage } \\
\text { of mitotane }\end{array}$} \\
\hline 12 months & & & & & 7.2 \\
\hline 16 months & 33 & & & & \\
\hline 60 months & 15 & & & 4 & \\
\hline
\end{tabular}

studies of TARTs and intensified glucocorticoid treatment have been published.

Recently, Bry Gauillard et al. reported the case of one CAH patient with TART who was successfully treated with mitotane to restore fertility (15). In our study, we report five patients with TARTs unresponsive to intensified glucocorticoid treatment, which for half of them were successfully treated with mitotane, thus demonstrating the long-term effects of mitotane to improve testicular function and fertility in CAH patients. Two of the five patients presented with hypogonadotropic hypogonadism due to poor hormonal control of $\mathrm{CAH}$. The difficulty in diagnosing hypogonadism in men with $\mathrm{CAH}$ is related to the fact that testosterone measured in serum is a mixture of testosterone of gonadal and adrenal origin. Undetectable or low gonadotrophins, associated with high levels of androstenedione and progesterone, should help lead to this diagnostic. Recovery of hypogonadotropic hypogonadism was achieved in these patients under mitotane therapy, thanks to control of the disease. Interestingly, these patients had normal inhibin B levels, suggesting intact Sertoli cells, in accordance with a previous study (10). These patients therefore probably had impaired endocrine and exocrine testicular function due to poor hormonal control and recent TART development. We demonstrate that, in the early stages of TART development, mitotane therapy can lower ACTH levels, reduce TART size and improve testicular function and fertility. Inhibin B may be a good indicator of the success of mitotane therapy.

On the contrary, in the later stages of TART development, this approach may be effective at reducing tumor size and improving adrenal function or controlling further growth and testicular damage, but is ineffective at improving testicular function and fertility, due to 
irreversible damage of the testis. This was the case in patients 2 to 4 , who presented testicular failure at baseline or discovered during the mitotane therapy. These patients exhibit low levels of inhibin B at baseline.

Mitotane is a metabolite of the pesticide and endocrine disruptor DDT (dichlorodiphenyltrichloroethane) and is classified as a teratogenic compound worldwide (12, 13). However, little is known about its effects on human development or its direct effect on oocytes or sperm. A recent study on four women having conceived while taking mitotane, or with detectable mitotane plasma levels, showed that exposure of these four children to mitotane in utero seemed to have no clear teratogenic effect (22). Two studies on reproductive toxicity of DDT in adult rats have showed direct testicular impact of these products, with a dose-dependent reduction of testicular weight and the number as well as the percentage of motile spermatozoa in the epididymis $(23,24)$. Interestingly, our study shows the absence of TART recurrence and persistence of spermatogenesis in the two responsive patients far from mitotane withdrawal. Therefore, conception is safe at a distance from treatment.

However, mitotane does cause irreversible chemical adrenalectomy, and is therefore only recommended in patients who show good compliance to the adrenal replacement therapy. Glucocorticoid doses should be increased during this treatment because it induces CYP3A4 in a major way, leading to more rapid inactivation of hydrocortisone, requiring a $50-100 \%$ increase in GC dose to avoid adrenal crisis, as experienced by two of our five patients (25). None of our patients experimented hypogonadism symptoms during mitotane treatment, as it has been reported in patients with adrenocortical cancer (25). Finally, liver function and cholesterol metabolism must be closely monitored in these patients (26).

In conclusion, patients with CAH should be informed about the risks of the development of TARTs, and consequently the high risk of infertility. They should be monitored regularly by ultrasound and should be offered systematic semen evaluations and cryopreservation. Mitotane could be used as a last resort in men with 21-hydroxylase deficiency and azoospermia in whom azoospermia is associated with large testicular adrenal rest tumors despite normal inhibin B levels, as it can improve endocrine and exocrine testicular function with residual effects lasting several years after withdrawal.

\section{Declaration of interest}

The authors declare that there is no conflict of interest that could be perceived as prejudicing the impartiality of this study.

\section{Funding}

This research was not funded by any specific grant from any funding agency in the public, commercial or non-profit sector.

\section{References}

1 Bachelot A, Grouthier V, Courtillot C, Dulon J \& Touraine P. MANAGEMENT OF ENDOCRINE DISEASE: Congenital adrenal hyperplasia due to 21-hydroxylase deficiency: update on the management of adult patients and prenatal treatment. European Journal of Endocrinology 2017176 R167-R181. (https://doi. org/10.1530/EJE-16-0888)

2 Bouvattier C, Esterle L, Renoult-Pierre $\mathrm{P}$, de la Perrière AB, Illouz F, Kerlan V, Pascal-Vigneron V, Drui D, Christin-Maitre S, Galland F et al. Clinical outcome, hormonal status, gonadotrope axis, and testicular function in 219 adult men born with classic 21-hydroxylase deficiency: a French national survey. Journal of Clinical Endocrinology and Metabolism 2015100 2303-2313. (https:// doi.org/10.1210/jc.2014-4124)

3 Engels M, Span PN, van Herwaarden AE, Sweep FCGJ, Stikkelbroeck NMML \& Claahsen-van der Grinten HL. Testicular adrenal rest tumors: current insights on prevalence, characteristics, origin, and treatment. Endocrine Reviews 201940 973-987. (https:// doi.org/10.1210/er.2018-00258)

4 Falhammar H, Nyström HF, Ekström U, Granberg S, Wedell A \& Thorén M. Fertility, sexuality and testicular adrenal rest tumors in adult males with congenital adrenal hyperplasia. European Journal of Endocrinology 2012166 441-449. (https://doi.org/10.1530/EJE-110828)

5 Engels M, Gehrmann K, Falhammar H, Webb EA, Nordenström A, Sweep FC, Span PN, van Herwaarden AE, Rohayem J, RichterUnruh A et al. Gonadal function in adult male patients with congenital adrenal hyperplasia. European Journal of Endocrinology 2018178 285-294. (https://doi.org/10.1530/EJE-17-0862)

6 Dumic M, Duspara V, Grubic Z, Oguic SK, Skrabic V \& Kusec V. Testicular adrenal rest tumors in congenital adrenal hyperplasiacross-sectional study of 51 Croatian male patients. European Journal of Pediatrics 2017176 1393-1404. (https://doi.org/10.1007/s00431-0173008-7)

7 Chihaoui M, Kanoun F, Chaker F, Yazidi M, Bouchrit K, Mizouni H, Feki M, Kharrat M \& Slimane H. Testicular adrenal rest tumours in young adult males with congenital adrenal hyperplasia: prevalence and impact on testicular function. Andrologia 201648 45-50. (https://doi.org/10.1111/and.12416)

8 Reisch N, Rottenkolber M, Greifenstein A, Krone N, Schmidt H, Reincke M, Schwarz HP \& Beuschlein F. Testicular adrenal rest tumors develop independently of long-term disease control: a longitudinal analysis of 50 adult men with congenital adrenal hyperplasia due to classic 21-hydroxylase deficiency. Journal of Clinical Endocrinology and Metabolism 201398 E1820-E1826. (https://doi.org/10.1210/jc.20123181)

9 Smeets EEJW, Span PN, van Herwaarden AE, Wevers RA, Hermus ARMM, Sweep FC \& Claahsen-van der Grinten HL. Molecular characterization of testicular adrenal rest tumors in congenital adrenal hyperplasia: lesions with both adrenocortical and Leydig cell features. Journal of Clinical Endocrinology and Metabolism 2015100 E524-E530. (https://doi.org/10.1210/jc.2014-2036)

10 Reisch N, Flade L, Scherr M, Rottenkolber M, Pedrosa Gil F, Bidlingmaier M, Wolff H, Schwarz HP, Quinkler M, Beuschlein F et al. High prevalence of reduced fecundity in men with congenital adrenal hyperplasia. Journal of Clinical Endocrinology and Metabolism 200994 1665-1670. (https://doi.org/10.1210/jc.2008-1414)

11 Reisch N, Scherr M, Flade L, Bidlingmaier M, Schwarz HP, MüllerLisse U, Reincke M, Quinkler M \& Beuschlein F. Total adrenal volume but not testicular adrenal rest tumor volume is associated with 
hormonal control in patients with 21-hydroxylase deficiency. Journal of Clinical Endocrinology and Metabolism 201095 2065-2072. (https:// doi.org/10.1210/jc.2009-1929)

12 Luton JP, Cerdas S, Billaud L, Thomas G, Guilhaume B, Bertagna X, Laudat MH, Louvel A, Chapuis Y \& Blondeau P. Clinical features of adrenocortical carcinoma, prognostic factors, and the effect of mitotane therapy. New England Journal of Medicine 1990322 1195-1201. (https://doi.org/10.1056/NEJM199004263221705)

13 Lubitz JA, Freeman L \& Okun R. Mitotane use in inoperable adrenal cortical carcinoma. JAMA 1973223 1109-1112.

14 Terzolo M, Pia A, Berruti A, Osella G, Alì A, Carbone V, Testa E, Dogliotti L \& Angeli A. Low-dose monitored mitotane treatment achieves the therapeutic range with manageable side effects in patients with adrenocortical cancer. Journal of Clinical Endocrinology and Metabolism 200085 2234-2238. (https://doi.org/10.1210/ jcem.85.6.6619)

15 Bry-Gauillard H, Cartes A \& Young J. Mitotane for 21-hydroxylase deficiency in an infertile man. New England Journal of Medicine 2014 371 2042-2044. (https://doi.org/10.1056/NEJMc1410041)

16 Benecke R, Vetter B \& De Zeeuw RA. Rapid micromethod for the analysis of mitotane and its metabolite in plasma by gas chromatography with electron-capture detection. Journal of Chromatography 1987417 287-294. (https://doi.org/10.1016/0378$4347(87) 80122-6)$

17 Cabrera MS, Vogiatzi MG \& New MI. Long term outcome in adult males with classic congenital adrenal hyperplasia. Journal of Clinical Endocrinology and Metabolism 200186 3070-3078. (https://doi. org/10.1210/jcem.86.7.7668)

18 Tanaka M, Enatsu N, Chiba K \& Fujisawa M. Two cases of reversible male infertility due to congenital adrenal hyperplasia combined with testicular adrenal rest tumor. Reproductive Medicine and Biology 2018 17 93-97. (https://doi.org/10.1002/rmb2.12068)

19 Claahsen-van der Grinten HL, Otten BJ, Sweep FC \& Hermus AR. Repeated successful induction of fertility after replacing hydrocortisone with dexamethasone in a patient with congenital adrenal hyperplasia and testicular adrenal rest tumors. Fertility and Sterility 200788 705.e5-705.e8. (https://doi.org/10.1016/j. fertnstert.2006.11.148)

20 Stikkelbroeck NM, Hermus AR, Suliman HM, Jager GJ \& Otten BJ. Asymptomatic testicular adrenal rest tumours in adolescent and adult males with congenital adrenal hyperplasia: basal and follow-up investigation after 2.6 years. Journal of Pediatric Endocrinology and Metabolism 200417 645-653. (https://doi.org/10.1515/ jpem.2004.17.4.645)

21 Claahsen-van der Grinten HL, Stikkelbroeck NM, Otten BJ \& Hermus AR. Congenital adrenal hyperplasia - pharmacologic interventions from the prenatal phase to adulthood. Pharmacology and Therapeutics 2011132 1-14. (https://doi.org/10.1016/j. pharmthera.2011.05.004)

22 Magkou D, Do Cao C, Bouvattier C, Douillard C, de Marcellus C, Cazabat L, Gérard M, Raffin-Sanson ML \& Young J. Foetal exposure to mitotane/Op'DDD: post-natal study of four children. Clinical Endocrinology 201889 805-812. (https://doi.org/10.1111/cen.13854)

23 Marouani N, Hallegue D, Sakly M, Benkhalifa M, Ben Rhouma K \& Tebourbi O. p,p'-DDT induces testicular oxidative stress-induced apoptosis in adult rats. Reproductive Biology and Endocrinology 201715 40. (https://doi.org/10.1186/s12958-017-0259-0)

24 Ben K, Tébourbi O, Krichah R \& Sakly M. Reproductive toxicity of DDT in adult male rats. Human and Experimental Toxicology 200120 393-397. (https://doi.org/10.1191/096032701682692946)

25 Chortis V, Taylor AE, Schneider P, Tomlinson JW, Hughes BA, O'Neil DM, Libé R, Allolio B, Bertagna X, Bertherat J et al. Mitotane therapy in adrenocortical cancer induces CYP3A4 and inhibits $5 \alpha$-reductase, explaining the need for personalized glucocorticoid and androgen replacement. Journal of Clinical Endocrinology and Metabolism 201398 161-171. (https://doi.org/10.1210/jc.2012-2851)

26 Fassnacht M, Dekkers OM, Else T, Baudin E, Berruti A, de Krijger R, Haak HR, Mihai R, Assie G \& Terzolo M. European Society of Endocrinology Clinical Practice Guidelines on the management of adrenocortical carcinoma in adults, in collaboration with the European Network for the study of adrenal tumors. European Journal of Endocrinology 2018179 G1-G46. (https://doi.org/10.1530/EJE-18-0608)

Received 10 July 2020

Revised version received 1 December 2020

Accepted 12 January 2021 